\title{
DIÁSPORA, INTEGRACIÓN SOCIAL Y ARRAIGO DE MIGRANTES EN SANTIAGO DE CHILE: IMAGINARIOS DE FUTURO EN LA COMUNIDAD VENEZOLANA.
}

\section{DIASPORA, SOCIAL INTEGRATION AND ROOTING OF MIGRANTS IN SANTIAGO DE CHILE: IMAGINARY OF FUTURE IN THE VENEZUELAN COMMUNITY.}

Nicolás Gissı Barbieri ${ }^{\star}$, Gonzalo Ghio Suárez ${ }^{\star \star}$ y Claudia Silva Dittborn ${ }^{\star \star \star}$

Resumen: El presente artículo tiene como propósito comprender los procesos de integración, arraigo y desarraigo de migrantes venezolanos residentes en Santiago de Chile, los que han llegado crecientemente durante los últimos cinco años, producto de la crisis económico-política que vive Venezuela. Buscamos ampliar los conocimientos sobre la movilidad Sur-Sur y en particular en América Latina. Presentamos resultados de una investigación cualitativa realizada en 2017 y 2018, a partir de tres ejes temporales: éxodo $y$ decisión de migrar hacia Chile; asentamiento y trayectorias; $y$ evaluación e imaginarios de futuro. Se concluye que hay una positiva integración social, siendo relevante tanto la percepción de lograr éxito laboral como la experiencia de participar en un paulatino proceso de mestizaje cultural, aportando a la construcción de convivencia intercultural en Santiago. Estas condiciones y situaciones están generando arraigo, al menos en el corto plazo.

* Universidad de Chile, Departamento de Antropología. Santiago, Chile. ngissi@uchile.cl

** Universidad de Chile. Santiago, Chile. gonzaloghio@gmail.com

*** Investigadora Programa de Estudios Sociales en Salud, Instituto de Ciencias e Innovación en Medicina ICIM, Universidad del Desarrollo. Santiago, Chile. claudiasilvad@yahoo.es 
Palabras clave: diáspora; integración; arraigo; imaginario; futuro.

Abstract: The purpose of this article is to understand the processes of integration, rootedness and uprooting of Venezuelan migrants living in Santiago, Chile, who have grown increasingly during the last five years, as a result of the economic-political crisis that Venezuela is currently experiencing. We seek to expand knowledge on South-South mobility and in particular in Latin America. We present the results of a qualitative research conducted in 2017 and 2018, based on three temporal axes: exodus and decision to migrate to Chile; settlement and trajectories; and evaluation and imaginary of the future. It is concluded that there is a positive social integration, being relevant both the perception of achieving job success and the experience of participating in a gradual process of cultural miscegenation, contributing to the construction of intercultural coexistence in Santiago. These conditions and situations are generating roots, at least in the short term.

Key words: diaspora; integration; rooting; imaginary; future.

\section{INTRODUCCIÓN}

Los desplazamientos dentro de América Latina han aumentado durante los últimos años, siendo Chile el país que concentra actualmente el mayor flujo inmigratorio regional (CEPAL-OIT, 2017), ya no sólo proviniendo desde las poblaciones fronterizas. Estas nuevas realidades generan múltiples desafíos para la convivencia pluricultural y el desarrollo social.

Según un informe emanado por el Instituto Nacional de Estadística (INE) y el Departamento de Extranjería y Migración (DEM) en febrero de 2019, se estima que a diciembre de 2018 residían en Chile 1.251.225 migrantes. Dicha estimación se realizó considerando los inmigrantes contabilizados en el Censo 2017 (ajustando por omisión); descontando a las personas que fallecieron o abandonaron el país (registros de la Policía de Investigaciones de Chile y del Registro Civil) $\mathrm{y}$ adicionando las personas que solicitaron permisos de residencia, habiendo llegado con una fecha posterior al censo (registros DEM). La nacionalidad venezolana sería, según esta estimación, la comunidad más numerosa en Chile, desplazando a los peruanos. De esta manera, 
los venezolanos representarían el 23\% de los migrantes en Chile, mientras los peruanos representarían el 17,9\%; los haitianos el 14,3; los colombianos el 11,7\% y los bolivianos el 8,6\%.

En el caso de Venezuela, debido a los conflictos políticos y violencia interna, la crisis económica, la escasez de bienes básicos, la alta inflación y la falta de medicamentos, han incrementado el malestar y la inseguridad, y en consecuencia, la movilidad durante el siglo XXI (Martínez y Orrego, 2016). Según los últimos datos entregados por Naciones Unidas, 4 millones de venezolanos se encuentran residiendo fuera de su país y 1.6 millones han salido desde 2015 (Cooperativa, 2018). Además, la histórica emigración hacia Estados Unidos, España y Panamá, se ha diversificado los últimos cinco años hacia Colombia, Perú, Chile y Ecuador, países que hasta el momento mantenían menores restricciones migratorias, las que están incrementando, dado el aumento en el flujo de migrantes (OIM, 2018).

La presencia venezolana en Chile tiene antecedentes desde antes del siglo XX, así como redes Chile-Venezuela a partir de los exiliados políticos, viviéndose hoy para muchos venezolanos "una vuelta de mano" (Rojas y Santoni, 2013). Sin embargo, el actual flujo migratorio se distingue, por una parte, en el fuerte incremento que ha tenido a partir del año 2014 y, por otra parte, en el relativamente alto nivel socioeconómico y educacional que tienden a tener los inmigrantes que llegan a Chile. Esto incide en los patrones que siguen sus trayectorias migratorias y la inserción que enfrentan en las comunas a las cuales tienen acceso en Santiago, así como en sus trabajos y lugares donde interactúan con los chilenos.

De este modo, el problema de investigación que aquí se plantea es: ¿Cuáles son las experiencias de vida y los factores socioculturales que participan en los procesos de integración y arraigo de migrantes provenientes de Venezuela que residen hoy en Chile?, teniendo como propósito interpretar y analizar sus procesos migratorios y de inserción en la ciudad de Santiago, considerando sus proyectos y trayectorias migratorias, con sus continuidades y contradicciones en el tiempo.

El presente artículo se organiza en tres partes. En un primer momento presentamos un marco teórico sobre fenómenos como la diáspora, la integración social y el arraigo, en segundo lugar, un análisis del flujo de la migración venezolana y una caracterización demográfica de este colectivo, y en tercer lugar, un análisis de 17 entrevistas en profundidad hechas a venezolanos/as residentes en Santiago, las que 
permiten explorar sus procesos migratorios, su inserción en la sociedad chilena y sus proyectos y eventual arraigo en Chile.

\section{Marco Teórico Referencial: diáspora, integración social y arraigo}

Al llegar al lugar de destino, las/os migrantes se enfrentan al desafío de insertarse a una sociedad que no les es completamente familiar. La progresiva participación en círculos sociales y en formas económicas, políticas y culturales, está afectada y a su vez afecta la experiencia de arraigo de las/os migrantes, quienes pueden orientarse en mayor medida hacia su sociedad de origen, hacia la sociedad de acogida (aunque lo sea temporalmente), hacia ambas de manera simultánea (tendiendo al transnacionalismo), o bien quedar marginado de las dos sociedades (González y Ramírez, 2017). ¿Qué circunstancias ocurren para que una persona desee y decida constituirse como un miembro más de esta "nueva" nación? (Bauman, 2009). Siguiendo a Portes y Zhou (2012) e Izquierdo (2000), podemos sostener que hay tres factores fundamentales que determinan las posibilidades de integrarse en la sociedad receptora:

1. La sociedad de destino, sus imaginarios colectivos y acciones: El ambiente en la sociedad de acogida es más o menos receptiva, dependiendo de su grado de tolerancia. Esto incluye los medios de opinión pública, centros de salud y escuelas, la existencia de organizaciones de apoyo y/o de grupos de rechazo así como el tipo de empresariado, el orden de género y el respeto de derechos.

2. La política migratoria del Estado receptor: la legislación y programas sociales generados desde el gobierno nacional y local. El tipo de visas a que se puede acceder y la validación de títulos.

3. El colectivo de migrantes: su solidez y organización social. La extensión y cohesión de la red de apoyo. El número de asociaciones.

La combinación de estos tres elementos genera distintos contextos de inserción, que facilitan o dificultan el establecimiento de las/os migrantes. La discriminación (xenofobia y racismo), la construcción de relaciones de dominación según clase, sexo y "raza" (Balibar y Wallerstein, 1988; Falquet, 2009; Tijoux, 2015), así como la nostalgia por el país de origen o bien el apego hacia el 
nuevo territorio, van moldeando las experiencias de inserción en la trayectoria migratoria. La configuración social que espera al recién llegado orientará su camino en una u otra dirección, modificando o reforzando su proyecto inicial: se asienta o re-emigra (migración circular o retorno), se mezcla o margina, se "ancla" o continúa des-arraigado. Si las personas que viven fuera de sus territorios de origen, son conscientes de su identidad nacional y reivindican su pertenencia más allá de donde estén asentadas, siendo el retorno un ideal a futuro, se trata de una diáspora (Grimson, 2015).

La necesidad de migrar se puede producir por diferentes motivos, pero particularmente cabe detenerse en el desarraigo "forzoso" que pueden sufrir hoy los individuos, particularmente en las periferias del sistema-mundo. Debido a guerras, desastres naturales, megaproyectos económicos y/o desempleo estructural, los sujetos y comunidades pueden quedar sin el hábitat originario, sin hogar (Sassen, 2015; Edson, 2016), sin Estado (Butler y Spivak, 2009), sin identidad cultural y sin empleo (Weil, 2014). Las probabilidades que estas situaciones se produzcan se relacionan con la posición del país en el sistema-mundo, siendo las poblaciones que se sitúan en las periferias las que son particularmente vulnerables a sufrir diferentes tipos de desastres ante la debilidad de sus Estados y economías (Wallerstein, 1991). A diferencia de lo que sucede en el centro, en la periferia una situación de crisis puede transformar bruscamente la estabilidad y el "progreso" en situaciones donde gran parte de la población padece graves carencias, que ponen en juego su seguridad alimentaria y su salud, entre otros.

Al llegar a sus destinos, los migrantes pueden "arraigarse" en su nuevo lugar de residencia. Aquí consideraremos como vínculos raigales el colectivo de origen o nación y/o etnia (Smith, 1997; Anderson, 1993), la familia, la profesión u oficio, el empleo y la adquisición de bienes (Stefoni y Bonhomme, 2015), las amistades, vecinos y las organizaciones locales. Estos distintos elementos del arraigo, los podemos asociar y clasificar en tres categorías: 1) al Estado/ territorio de nacimiento (colectivo de origen o nación y/o etnia); 2) al individuo y su trayectoria (familia, amigos/redes sociales nacionales y/o internacionales, profesión, empleo, propiedades); y 3) al Estado y sociedad de destino, sea ésta temporal o definitiva (trato al colectivo migrante, demanda laboral de su profesión u oficio, barrio/vecinos).

Toda migración implica un proyecto, individual y familiar. Sueños y aspiraciones se enfrentan durante el proceso migratorio a realidades 
personales y sociales que devendrán en facilitadores o barreras para el cumplimiento de sus expectativas. Para ello hay que considerar las condiciones y las limitantes objetivas que influyen en el logro de una buena vida. El concepto de proyecto migratorio constituye la expresión más completa de un proceso que vincula origen, trayecto y destino - o decisión de partir, recorrido y establecimiento (temporal/ definitivo)- . Tal transición incluye continuas negociaciones que ponen en tensión distintos contextos, relaciones y actores: los que se mueven y los que se quedan, intermediarios y receptores directos (familiares o empleadores), así como instituciones y organizaciones disímiles (Izquierdo, 2000; Bourdieu y Wacquant, 2012). Esta noción de proyecto migratorio crea y valoriza cierta coherencia estratégica en los discursos de migrantes, sin embargo, tiende a esconder los procesos de transformación que ocurren durante el itinerario, que se generan en el contexto o bien debido al cambio subjetivo del individuo. En este punto, la noción de trayectoria permite analizar los periplos en los proyectos migratorios y distinguir las condiciones de emergencia de lo imprevisible e irreversible en tales trayectorias

El imaginario, esto es, las tramas de significaciones que estructuran la memoria, la experiencia social e individual, y constituyen la realidad en una determinada sociedad y época (Castoriadis 1998), de construcción de futuro (Appadurai, 2015) se conforma así día a día en la vida cotidiana, en lo que de B. Sousa Santos (2010) denomina una "sociología de las emergencias", esto es, un futuro de las posibilidades plurales y concretas que se van creando en el presente, a partir de sus proyectos, trayectorias y aspiraciones.

\section{MIGRACIÓN VENEZOLANA A CHILE: CARACTERÍSTICAS DEMOGRÁFICAS Y FLUJO MIGRATORIO}

A continuación, caracterizaremos la migración de ciudadanos/ as venezolanos/as en Chile a partir de las estadísticas del DEM disponibles en las bases de datos publicadas en su página web ${ }^{1}$. Las cifras que a continuación se presentan surgen del procesamiento de estas bases, que contienen información sobre las Visas Temporales

1 Las bases de datos están disponibles en http://www.extranjeria.gob.cl/ estadisticas-migratorias/ y fueron extraídas el 25 de mayo de 2018. 
y Permanencias Definitivas otorgadas en el período 2005 a 2017. Es importante tener presente que la información da cuenta de los permisos de residencia otorgados, no de las personas que los han obtenido, ya que una misma persona puede obtener más de un permiso, especialmente más de una visa pero también más de una Permanencia Definitiva ${ }^{2}$. Además, para que una persona obtenga una Permanencia Definitiva tiene que haber solicitado previamente una o más Visas Temporales. En las bases de datos publicadas no hay variables que permitan identificar estas situaciones y obtener una información referente a personas.

Las dos variables de la estructura demográfica de la población son el sexo y la edad. Para caracterizar a la población de venezolanos según estas variables utilizaremos las bases de datos de las Permanencias Definitivas para el período 2005 a 2017, ya que tienen menos repetición de casos que en las Visas Temporales. En la siguiente tabla se aprecia la distribución según sexo y edad ${ }^{3}$. Se puede observar que la migración venezolana tiene una distribución pareja con relación a la variable sexo, con un $51 \%$ de mujeres y un $49 \%$ de hombres, y que se concentra en los grupos de edad laboral, sumando un $84,8 \%$ las personas entre 20 y 59 años, y particularmente concentrándose en el grupo de 20 a 39 años, con un 70,5\% de los casos.

\begin{tabular}{|l|r|r|r|r|}
\hline \multicolumn{5}{|c|}{ Tabla I: Sexo y edad de quienes adquieren una Permanencia } \\
Definitiva \\
\hline & \multicolumn{1}{|c|}{ Mujeres } & \multicolumn{1}{c|}{ Hombres } & Total & $\%$ Edad \\
\hline 0 a 4 & 312 & 318 & 630 & 3,09 \\
\hline 5 a 9 & 476 & 494 & 970 & 4,75 \\
\hline 10 a 19 & 511 & 523 & 1034 & 5,06 \\
\hline 20 a 29 & 3177 & 2799 & 5976 & 29,27 \\
\hline 30 a 39 & 4077 & 4333 & 8410 & 41,19 \\
\hline 40 a 49 & 1095 & 1104 & 2199 & 10,77 \\
\hline 50 a 59 & 437 & 290 & 727 & 3,56 \\
\hline 60 a 69 & 241 & 107 & 348 & 1,70 \\
\hline 70 o más & 85 & 37 & 122 & 0,60 \\
\hline Total & 10411 & 10005 & 20416 & 100,00 \\
\hline$\%$ Sexo & 50,99 & 49,01 & 100,00 & \\
\hline $\begin{array}{l}\text { Fuente: elaboración propia en base a procesamiento de Bases } \\
\text { de Datos del DEM. }\end{array}$ \\
\hline
\end{tabular}

2 Esto puede ocurrir cuando una persona con permanencia definitiva deja el país por un tiempo superior a un año corrido.

3 La edad es la que tenían las personas al momento de obtener el documento. 
En la siguiente tabla se aprecian las regiones de residencia de los/as venezolanos/as que han obtenido un permiso de permanencia definitiva. El colectivo venezolano está preferentemente concentrado en la Región Metropolitana, y las siguientes regiones con mayor presencia también son de la zona central, Valparaíso y el Maule. Esta distribución es diferente a la del conjunto de inmigrantes, que también tienen como primera región de residencia a la Metropolitana, pero en un porcentaje muy inferior, y luego tienden a residir en las regiones del norte del país, especialmente Antofagasta y Tarapacá.

\begin{tabular}{|l|r|r|}
\hline \multicolumn{3}{|c|}{$\begin{array}{c}\text { Tabla II: Distribución porcentual por regiones } \\
\text { de quienes adquieren una Permanencia } \\
\text { Definitiva, 2005-2017 }\end{array}$} \\
\hline Regiones & Venezolanos & Todos \\
\hline Arica y Parinacota & 0,19 & 2,91 \\
\hline Tarapacá & 0,46 & 6,82 \\
\hline Antofagasta & 1,17 & 12,20 \\
\hline Atacama & 0,32 & 1,63 \\
\hline Coquimbo & 0,91 & 1,64 \\
\hline Valparaiso & 2,83 & 3,28 \\
\hline Metropolitana & 88,42 & 65,44 \\
\hline O'Higgins & 1,16 & 1,06 \\
\hline Maule & 1,76 & 0,90 \\
\hline Biobío & 1,33 & 1,60 \\
\hline De la Araucanía & 0,41 & 0,68 \\
\hline De los Rios & 0,18 & 0,27 \\
\hline De los Lagos & 0,46 & 0,84 \\
\hline Aysén & 0,11 & 0,17 \\
\hline Magallanes & 0,30 & 0,55 \\
\hline Total general & 100,00 & $\mathbf{1 0 0 , 0 0}$ \\
\hline Fuente: elaboración propia en base a \\
procesamiento de Bases de Datos del DEM. \\
\hline
\end{tabular}

En cuanto al flujo migratorio, en los últimos años hay un cambio radical en la magnitud del flujo migratorio de venezolanos/as.

\begin{tabular}{|l|r|r|r|r|r|r|r|r|r|r|r|r|r|}
\hline \multicolumn{10}{|c|}{ TABLA III: Permanencias Definitivas y Visas Temporales otorgadas a venezolanos/as en cada año. } \\
\hline Año & 2005 & 2006 & 2007 & 2008 & 2009 & 2010 & 2011 & 2012 & 2013 & 2014 & 2015 & 2016 & 2017 \\
\hline PD & 184 & 179 & 155 & 187 & 337 & 333 & 367 & 511 & 552 & 685 & 1349 & 3704 & 11873 \\
\hline VT & 379 & 434 & 615 & 631 & 677 & 758 & 1089 & 1249 & 1463 & 2872 & 8381 & 22921 & 73386 \\
\hline
\end{tabular}


La tabla muestra que hasta 2013 el aumento del flujo migratorio de venezolanos/as fue poco significativo. Esto cambia drásticamente a partir del año 2014 para las Visas Temporales, donde estos permisos casi se duplican con respecto a 2013, marcando el inicio de una tendencia al aumento. Este crecimiento en las Visas Temporales de 2014 anticipa el aumento en las Permanencias Definitivas (que se pueden obtener luego de al menos una Visa Temporal), las que comienzan a aumentar de manera significativa a partir de 2015. La siguiente tabla muestra los porcentajes de aumento interanual en la entrega de ambos tipos de permisos.

\begin{tabular}{|l|r|r|r|r|r|r|r|r|r|r|r|r|}
\hline \multicolumn{10}{|c|}{ TABLA IV: Porcentaje de crecimiento interanual de Permanencias Definitivas y Visas Temporales otorgadas a venezolanos/as. } \\
\hline & $2005-6$ & $2006-7$ & $2007-8$ & $2008-9$ & $2009-10$ & $2010-11$ & $2011-12$ & $2012-13$ & $2013-14$ & $2014-15$ & $2015-16$ & $2016-17$ \\
\hline PD & $-2,7$ & $-13,4$ & 20,6 & 80,2 & $-1,2$ & 10,2 & 39,2 & 8,0 & 24,1 & 96,9 & 174,6 & 220,5 \\
\hline VT & 14,5 & 41,7 & 2,6 & 7,3 & 12,0 & 43,7 & 14,7 & 17,1 & 96,3 & 191,8 & 173,5 & 220,2 \\
\hline
\end{tabular}

Esta tabla expone que, con la excepción del aumento de las Permanencias Definitivas entre 2008 y 2009, explicada por el proceso de regularización efectuado en 2007 en el cual personas en condición irregular adquirieron Visas Temporales (DEM 2017), los aumentos interanuales superiores a $50 \%$ sólo se producen a partir de 2013-2014 para las Visas Temporales y de 2014-2015 para las Permanencias Definitivas. Las tasas de incremento interanual de la inmigración se incrementan en los años siguientes, hasta superar el 200\% entre 2016 y 2017 en ambos documentos. Este incremento se refleja en que las Permanencias Definitivas y Visas Temporales otorgadas en 2017, superan la suma de los respectivos documentos otorgados entre 2005 y 2016.

Entre 2005 y 2013, las Permanencias Definitivas aumentaron en un $200,0 \%$ y las Visas Temporales un $286 \%$. Este crecimiento es algo superior al registrado por el conjunto de los inmigrantes, que en el mismo período tienen un aumento en las Permanencias Definitivas de $118,2 \%$ y en las Visas Temporales de 218,7\%. Esto cambia drásticamente en los siguientes años, ya que entre 2013 y 2017, en sólo 4 años, las Permanencias Definitivas aumentan un $2050,9 \%$ y las Visas Temporarias un $4916,1 \%$, cifras muy superiores al aumento que tuvieron para el conjunto de nacionalidades de $237,7 \%$ y $102,5 \%$, respectivamente.

Este crecimiento posicionó a los venezolanos/as, por primera vez, como el colectivo que recibió más Visas Temporales el año 2017. 

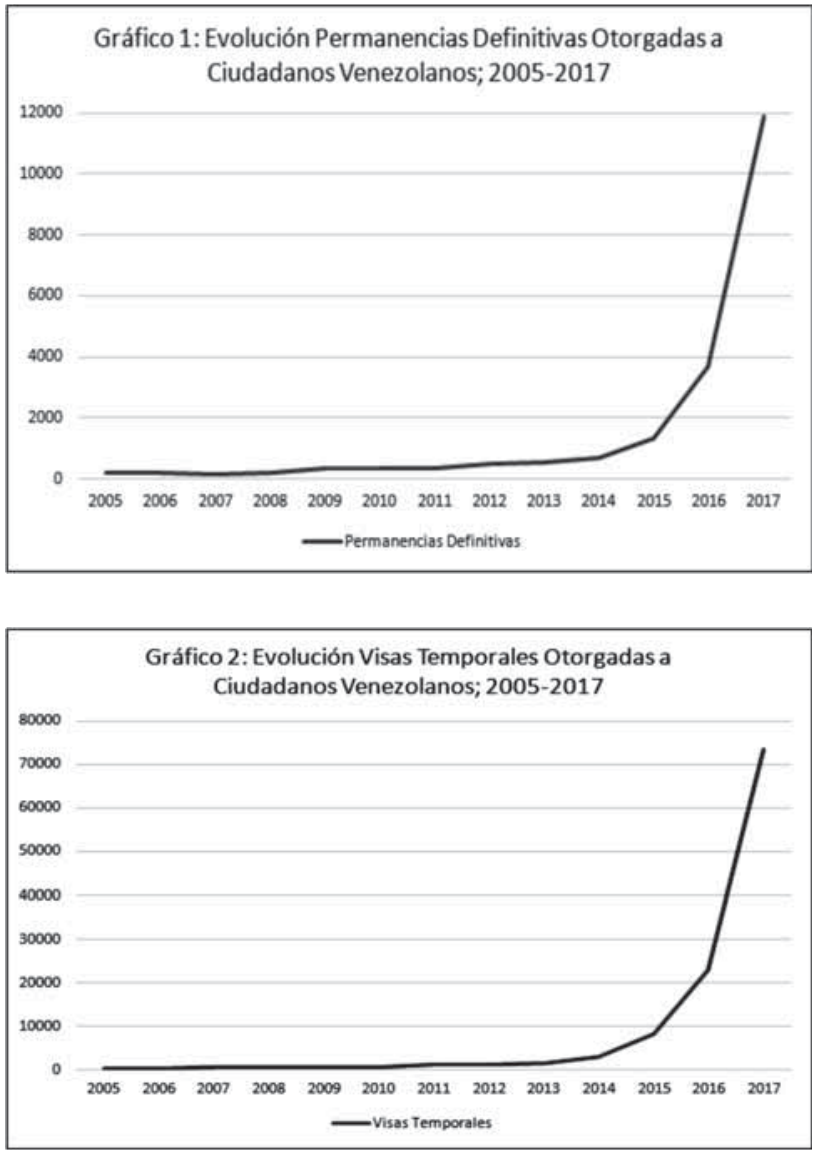

En cuanto a las Permanencias Definitivas, en 2017 la comunidad venezolana fue la tercera en cantidad de permisos obtenidos, 11.873, sólo superados por peruanos/as (22.433) y colombianos/ as (18.938). Cabe señalar que al año 2017 los/as venezolanos/as obtuvieron un $27,4 \%$ del total de las Visas Temporales y un 13,5\% de las Permanencias Definitivas, lo que contrasta con el año 2005, cuando sólo representaron $0,9 \%$ y 1,6\% respectivamente. 
Estos datos muestran el impacto que ha tenido la crisis que se ha agudizado en los últimos años en Venezuela. Desde un punto de vista demográfico, se puede sostener que la información apunta a que este flujo de población se continuará incrementando, de no mediar importantes cambios económicos, políticos y sociales en Venezuela o Chile. Al respecto cabe esperar aún qué impacto tendrá el proyecto de Ley de Migraciones que el gobierno chileno ha presentado al congreso el año $2018^{4}$, y las medidas administrativas que han puesto en funcionamiento, una de las cuales es la "visa democrática", para la inmigración desde Venezuela ${ }^{5}$.

En las siguientes tablas se muestra el cambio demográfico en las Permanencias Definitivas, tomando el período 2005-2011 como de la original dinámica migratoria, y el 2015-2017 como el de la nueva dinámica (considerando los años 2012 a 2014 como una "transición”).

\begin{tabular}{|l|r|r|}
\hline \multicolumn{3}{|c|}{$\begin{array}{c}\text { Tabla V: Distribución Permanencias Definitivas } \\
\text { por grupos de edad, según periodos }\end{array}$} \\
\hline & $2005-2011$ & $2015-2017$ \\
\hline 0 a 4 & 2,76 & 3,15 \\
\hline 5 a 9 & 6,14 & 4,48 \\
\hline 10 a 19 & 10,39 & 4,27 \\
\hline 20 a 29 & 19,92 & 31,13 \\
\hline 30 a 39 & 33,07 & 42,31 \\
\hline 40 a 49 & 17,05 & 9,57 \\
\hline 50 a 59 & 6,31 & 3,09 \\
\hline 60 a 69 & 2,81 & 1,52 \\
\hline 70 o más & 1,55 & 0,47 \\
\hline $\begin{array}{l}\text { Fuente: Elaboración propia en base a } \\
\text { procesamiento de Bases de Datos del DEM }\end{array}$ \\
\hline
\end{tabular}

4 El proyecto imposibilita el cambio de categoría migratoria al interior del país (pasar de turista a residente). En la actualidad la gran mayoría de los migrantes que ingresan al país lo hacen como turistas y luego con un contrato de trabajo solicitan una residencia temporal. Si la nueva ley imposibilita el cambio de categoría migratoria se espera un aumento de la población irregular.

5 La Visa de Orientación Democrática es una alternativa adicional a las visas existentes para los ciudadanos de Venezuela. Es una visa que se solicita en origen y posibilita ingresar a Chile como residente temporal. Es importante destacar que mientras no cambie la Ley, los/as venezolanos/as pueden seguir ingresando como turistas y solicitar al interior del país la residencia temporal. 


\begin{tabular}{|l|r|r|}
\hline \multicolumn{3}{|c|}{$\begin{array}{c}\text { Tabla VI: Distribución de las Permanencias } \\
\text { Definitivas por sexo, según períodos }\end{array}$} \\
\hline & $2005-2011$ & $2015-2017$ \\
\hline Mujeres & 57,18 & 49,72 \\
\hline Hombres & 42,82 & 50,28 \\
\hline \multicolumn{2}{|l|}{$\begin{array}{l}\text { Fuente: Elaboración propia en base a } \\
\text { procesamiento de Bases de Datos del DEM }\end{array}$} \\
\hline
\end{tabular}

Las tablas exponen un cambio en el sexo y los grupos de edad a los que pertenecen los migrantes. En 2015-2017 hay una importante reducción en la brecha entre mujeres y hombres, prácticamente igualándose el porcentaje en la nueva dinámica migratoria, frente a la diferencia de casi 15 puntos porcentuales que había en el primer período en favor de las mujeres. En relación a la edad, si bien en 2005-2011 ya había una concentración en los grupos entre 20 y 39 años, con un 53\% de las personas en este tramo, en 2015-2017 esta proporción llega al 73,4\%.

\section{INTEGRACIÓN Y ARRAIGO DE LOS VENEZOLANOS/AS EN CHILE}

En este apartado realizamos un análisis de 17 entrevistas en profundidad hechas a venezolanos/as residentes en Santiago, las que permiten aproximarse a sus subjetividades, conocer sus discursos e imaginarios sobre la salida de su país, la integración o exclusión en la sociedad chilena, la evaluación de la experiencia migratoria, así como sus proyectos y eventual arraigo en Chile.

\section{Aspectos Metodológicos}

A continuación se presentan resultados de una investigación mediante entrevistas cualitativas, cuyo propósito es indagar los procesos individuales y colectivos de integración social y arraigo, teniendo como punto de partida una doble opción metodológica: 
1) la etnografía, que nos permite tanto comprender las particulares lógicas sociales y culturales que emergen de las experiencias migratorias como conocer las trayectorias existentes de y entre los migrantes. Nos guía también, 2) el relacionalismo metodológico (Bourdieu y Wacquant, 2012; De Certeau, 2000), enfoque que sostiene la primacía de las relaciones y procesos por sobre la mirada de los sistemas o agentes, buscando la disposición del entretejido social. De este modo, la unidad de análisis son los individuos, teniendo presentes sus redes de sociabilidad que se van constituyendo día a día.

El trabajo de terreno buscó lograr un adecuado equilibrio entre "inmersión" (trabajo de campo) y extensión (número de entrevistados). Para ello se realizó un muestreo teórico e intencional, adaptado para la comparación entre casos, con el fin de mostrar una diversidad de experiencias, hasta cumplir la saturación de los datos.

Optamos por la Región Metropolitana (RM) pues concentra sobre la mitad de los migrantes en Chile, siendo un $75 \%$ en el caso venezolano $(\mathrm{DEM}, 2018)^{6}$. El trabajo de campo se llevó a cabo en seis comunas, dando cuenta de la heterogeneidad social y urbana de la capital: Santiago-Centro (central), Estación Central, Independencia, San Miguel (peri-centrales), Ñuñoa (sector oriente o de alta renta) y El Bosque (periférica), comunas en las que se están desarrollando nuevas formas de segregación y mezcla social, debido a la modificación en la escala de la segregación social en Santiago durante la última década (Ortiz y Escolano, 2013).

\section{Cuadro de sujetos/as entrevistados/as}

Se realizaron un total de 17 entrevistas en profundidad, entre septiembre de 2017 y marzo de 2018, nueve mujeres y ocho hombres, todos de color de piel "blanca"/mestizos/as, por lo que este análisis no se detiene en las diferencias que pueden surgir en la trayectoria migratoria a causa del fenotipo de los migrantes. A continuación se presenta una tabla que sistematiza los principales datos del perfil socio-demográfico de los/as interlocutores/as.

6 Si bien la proporción de venezolanos residentes en dicha región es muestralmente significativa, podría haber algunos matices respecto de las vivencias de inmigrantes residentes en otras regiones del país. 


\begin{tabular}{|c|c|c|c|c|c|c|}
\hline Nombre & Sexo & Edad & Educación & Ocupación & $\begin{array}{l}\text { Comuna de } \\
\text { residencia }\end{array}$ & $\begin{array}{c}\text { Año llegada } \\
\text { a Chile }\end{array}$ \\
\hline Javier & $\mathrm{H}$ & 28 & Gastronomía & $\begin{array}{l}\text { Ayudante de } \\
\text { cocina }\end{array}$ & Santiago & 2015 \\
\hline Vanessa & M & 30 & $\begin{array}{l}\text { Aduanay } \\
\text { comercio } \\
\text { exterior }\end{array}$ & Venta de seguros & Santiago & 2015 \\
\hline Jenny & M & 41 & $\begin{array}{c}\text { Diseño de } \\
\text { modas }\end{array}$ & $\begin{array}{l}\text { Dueña de } \\
\text { negocio }\end{array}$ & Ñuñoa & 2014 \\
\hline Pablo & $\mathrm{H}$ & 33 & Enfermería & Venta de seguros & Independencia & 2016 \\
\hline Juan & H & 47 & Arquitectura & $\begin{array}{c}\text { Empleado en } \\
\text { empresa }\end{array}$ & Ñuñoa & 2015 \\
\hline Mónika & M & 38 & $\begin{array}{c}\text { Técnico } \\
\text { informática }\end{array}$ & $\begin{array}{c}\text { Técnico de } \\
\text { sistemas }\end{array}$ & Independencia & 2015 \\
\hline Luis & $\mathrm{H}$ & 22 & $\begin{array}{l}\text { Sin estudios } \\
\text { superiores }\end{array}$ & Vendedor & Santiago & 2015 \\
\hline Leither & $\mathrm{H}$ & 29 & $\begin{array}{c}\text { Comercio } \\
\text { Internacional }\end{array}$ & Vendedor & Ñuñoa & 2015 \\
\hline José & $\mathrm{H}$ & 36 & $\begin{array}{l}\text { Ingeniería } \\
\text { Comercial }\end{array}$ & Vendedor & Santiago & 2015 \\
\hline Héctor & H & 30 & Sociología & $\begin{array}{l}\text { Vendedor/ } \\
\text { Panadero }\end{array}$ & El Bosque & 2016 \\
\hline Juan Carlos & $\mathrm{H}$ & 30 & $\begin{array}{c}\text { Contador } \\
\text { Público }\end{array}$ & $\begin{array}{l}\text { Contador/ } \\
\text { Vendedor }\end{array}$ & Santiago & 2015 \\
\hline Ana & $M$ & 45 & $\begin{array}{c}\text { Administració } \\
n\end{array}$ & $\begin{array}{l}\text { Control de } \\
\text { inventarios }\end{array}$ & Ñuñoa & 2015 \\
\hline Isabel & $M$ & 30 & Psicóloga & Consultora & Santiago & 2016 \\
\hline Joselis & M & 34 & $\begin{array}{l}\text { Profesora de } \\
\text { matemáticas }\end{array}$ & $\begin{array}{l}\text { Profesora de } \\
\text { matemáticas }\end{array}$ & San Miguel & 2016 \\
\hline Marcela & $M$ & 40 & Psicóloga & $\begin{array}{l}\text { RR.HH. en } \\
\text { empresa }\end{array}$ & $\begin{array}{c}\text { Estación } \\
\text { Central }\end{array}$ & 2015 \\
\hline Ysmary & $M$ & 47 & $\begin{array}{l}\text { Sin estudios } \\
\text { superiores }\end{array}$ & $\begin{array}{l}\text { Secretaria } \\
\text { recepción en } \\
\text { centro de salud }\end{array}$ & Santiago & 2016 \\
\hline Alexy & M & 52 & $\begin{array}{c}\text { Doctorado en } \\
\text { Ciencias } \\
\text { Politicas }\end{array}$ & $\begin{array}{c}\text { Call center } \\
\text { (cargo } \\
\text { administrativo) }\end{array}$ & Santiago & 2017 \\
\hline
\end{tabular}

En las próximas páginas presentamos el análisis de datos de acuerdo a tres grandes puntos, correspondientes a la clasificación de los distintos elementos del arraigo (indicados en el marco teórico) en tres categorías: 1) La partida de Venezuela: el éxodo; 2) Asentamiento en Chile: "Empezar de cero"; y 3) Evaluación de la experiencia migratoria e imaginarios de futuro: ¿arraigo? 


\section{LA PARTIDA DE VENEZUELA: EL ÉXODO}

Pese a que han llegado a Chile migrantes de distintas regiones de Venezuela, hay dos ciudades y estados que destacan: Caracas, Distrito Capital y Maracaibo, capital del Zulia, en el noroeste del país, limitando al oeste con Colombia. Caracas y Maracaibo (ciudad petrolera) son las dos ciudades más grandes y pobladas de Venezuela. Esto coincide con el reciente Informe sobre la movilidad humana venezolana (Bermúdez et al., 2018) en que se indica que emigran mayoritariamente desde el Distrito Capital y los distritos vecinos (Aragua y Carabobo) y desde las regiones fronterizas con Colombia (Zulia y Táchira, así como las cercanas Mérida y Lara).

Sobre su vida en Venezuela, la mayoría de los/as entrevistados/ as dan cuenta de una buena situación económica y estabilidad laboral en su área de estudios. Provienen de familias con uno o más parientes que han realizado estudios superiores. Quienes no tienen padres profesionales son nativos principalmente del interior del país (Táchira, Mérida y Lara, al sur de Zulia).

La principal motivación que genera la salida del país es la actual situación de deterioro político-económico venezolana. Esta realidad ha operado como un catalizador de la emigración y del no querer volver, al menos mientras no mejoren las condiciones de vida. La actual crisis, según Juan, era algo que se venía arrastrando desde años atrás y que ya lo había hecho plantearse la migración:

"Yo creo que cada uno se empezó a preocupar a tiempos distintos, nos vinimos hace dos años para acá pero yo tenía como siete u ocho años que me quería ir del país ..." (47, arquitecto).

En este sentido, los entrevistados plantean diferentes aspectos que permiten caracterizar la situación venezolana, como la inseguridad, escasez de bienes y la alta inflación, por lo que hoy "todos se están yendo", tal como Javier señala:

“... como en el dos mil catorce más o menos que ahí como que la situación en Venezuela empeoró pero no sé, del cielo a la tierra, no fue gradual como en los años anteriores sino que como que todo explotó entonces de repente veías que el costo de la vida estaba aumentando muchísimo más, que de repente no conseguías los productos básicos en el supermercado, que la delincuencia había aumentado... si tenía de cierto modo el plan 
de emigrar, eso como que aceleró la situación muchísimo más" (28, cocina).

Debido a la falta de productos, Ana plantea que la situación ha terminado en un intercambio de objetos entre amigos y vecinos sin importar mucho el costo de cada uno.

“...y por un grupo de whatsapp, 'tengo aceite', 'quién tiene leche', 'yo tengo leche', entonces nos vemos en tal sitio, yo te doy el aceite, tú me das la leche, chao, sin importar el costo" (45, administradora).

En términos de seguridad, los entrevistados plantean que la percepción de riesgo va aumentando, como lo declara Vanessa, provocando malestar e incertidumbre:

"La inseguridad es brutal, o sea, yo llegaba rezando a mi casa para que no me pasara nada y salía rezando para que no me pasara nada..." (Vanessa, 30, aduana y comercio exterior).

Otro factor importante que señalan los interlocutores es el alza que han tenido los precios de los productos y la brecha respecto al sueldo que estaban recibiendo, lo que no se lograba subsanar con el aumento de salarios:

"Me vine en el dos mil quince, eso en parte porque el sueldo ya no estaba alcanzando para nada... lo que comprabas para el mes para comida era muchísimo menos de lo que te alcanzaba antes" (Vanessa, 30, aduana y comercio exterior).

Los/as migrantes venezolanos/as eligen Chile por la seguridad, estabilidad económica, libertad y posibilidades que ofrece el país, denominándolo comúnmente como "el mejor país" de Latinoamérica.

\section{ASENTAMIENTO EN CHILE: "EMPEZAR DE CERO"}

\subsection{Redes sociales previas y trámites migratorios}

Los/as entrevistados/as concuerdan en que el proceso de procedimientos migratorios en Venezuela y Chile es lento, engorroso y caro, que requiere conocimiento y tiempo, aunque más fácil acá 
que en otros países de llegada. Algunas personas, como Pablo, incluso pagan a "gestores", para que les ayuden a agilizar el papeleo:

"En Venezuela es un proceso bastante complejo, lento, tienes que ayudarte con gestores, con gente que te hace ese trámite y obviamente cuesta plata. Y me tocó, me tocó arriesgar, pagar bastante dinero para que me hicieran eso y en dos semanas me tuvieran los documentos..." (33, enfermería).

Además de la legalización de los documentos, algunos interlocutores plantean que tuvieron que vender sus propiedades para juntar el dinero que les permitiera viajar, como indica Jenny:

“Tenía un departamento, lo vendí, vendí mi carro y con eso me vine" (41, diseño de modas).

Todos/as los/as venezolanos/as han llegado al país con visa de turista y una vez en Chile, debieron buscar una fuente laboral donde conseguir un contrato con el cual gestionar una "visa por motivos laborales"7 (como también pedir otras visas como las de profesionales y técnicos o de vínculo con chileno o residente permanente o sujeta a contrato) pudiendo después de un año solicitar la permanencia definitiva:

"Sí, primero te dan permiso de turista, o permiso de trabajo de turista mientras estás tramitando la visa temporaria, entonces ya ahí a los seis meses me dieron la temporaria, cumplí las ocho cotizaciones de AFP al otro, en mi caso lo hice al año y ahí pedí la definitiva y me salió ahora en agosto" (Vanessa, 30, aduana y comercio exterior).

El proceso de trámites en Chile era caracterizado como fácil y de bajo costo, comparado con otros países, pero con el evidente aumento en la llegada de inmigrantes al país, después de 2014 la realización de los trámites se ha ralentizado, como expresa Luis:

"Bueno, si lo comparamos con otros lugares, aquí es muy fácil. Actualmente, más engorroso porque ha llegado una cantidad de

7 La administración del presidente Piñera dejó sin efecto esta visa a partir de abril 2018, con lo que la única alternativa de visa de trabajo es la "visa sujeta a contrato" que plantea mayores restricciones a la contratación 
inmigrantes increíble... yo me acuerdo que la primera vez que fui a hacer mis papeles no me demoré más de treinta minutos. La última vez que fui para la visa definitiva me tomé un día entero" (22, sin estudios superiores).

\section{2. b) Buscando un lugar: comunas y barrios donde residen en Santiago}

Los venezolanos suelen llegar a Chile a vivir junto con familiares o amigos que habían viajado antes. De esta forma, llegan provisoriamente a alguna comuna desde donde buscan trabajo y estabilizarse económicamente. Respecto a las comunas de residencia, de acuerdo a Atisba (2018), la comuna más prevalente donde viven quienes han recibido Permanencias Definitivas es Santiago. Luego, figuran las comunas de Estación Central, Independencia, Ñuñoa, San Miguel, Huechuraba y Providencia, esto es, zonas asociadas a la clase media y media alta, lo que coincide con los discursos de los entrevistados. Junto a Santiago, las comunas peri-centrales más comunes son Estación Central, Independencia y San Miguel, y surgen también algunas periféricas, siendo las que más se repiten El Bosque, Huechuraba y Conchalí. Destacan también algunas calles por la concentración de venezolanos:

"Pero Santiago centro es como por zona, entonces, aquí en [calle] Carmen le dicen 'Carmenzuela' por ejemplo, porque hay muchos venezolanos” (Pablo, 33, enfermería).

Llegados a una comuna, durante el proceso de inserción van conociendo nuevas zonas urbanas, pensando en independizarse y superar cierto hacinamiento. Las comunas elegidas son Santiago Centro (especialmente en dirección norte-sur, entre la Alameda y Santa Isabel, y en dirección este-oeste, entre Vicuña Mackenna y Santa Rosa, donde se han concentrado) ${ }^{8}$, Nuñoa y Providencia. El cambio

8 De acuerdo a los resultados del Censo 2017, en Santiago Centro residen 80.094 personas extranjeras. En el Barrio Santa Isabel viven 6.150 venezolanos; en la colindante calle San Isidro residen 5.265 y en el Barrio Santa Ana se ubican 3.549, conviviendo con 1.507 colombianos. También han llegado los venezolanos al eje Bulnes-Almagro, y en la comuna de Estación Central, al Barrio Estación (Atisba, 2018). 
de residencia suele implicar también el paso desde un departamento compartido a uno de arriendo personal o familiar, así como desde una torre muy alta a un edificio más pequeño y acogedor o a una casa, con más espacio. En Santiago e Independencia especialmente se suelen describir edificios y barrios en que es notoria la presencia de venezolanos, así como de colombianos y dominicanos.

Se plantea que cuando llegaron no era tan habitual ver migrantes, pero que durante los dos últimos años, la presencia de otros latinoamericanos se ha vuelto más visible, encontrándose — por ejemplo en los supermercados- más extranjeros incluso que chilenos:

"O sea a comparación de hace dos años y un poquito más, no era tan común ver por lo menos venezolanos pero ahora no sé, tú vas en el ascensor o vas caminando por la calle, en el supermercado, los que quedan cerca, los mini-market, en todos lados consigues venezolanos" (Javier, 28, cocina).

\subsection{Trayectorias, desarraigos y re-arraigos: lo que se deja y lo que se retoma}

"Hay que empezar de cero", es un dicho muy característico de los migrantes venezolanos. Tiene que ver con el perfil que los caracteriza como profesionales, algunos altamente calificados, pero que para insertarse en la sociedad chilena tienen que empezar con trabajos que muchos "nunca se imaginaron haciendo". Todos tienen la intención de poder dedicarse a su profesión y recuperar el estatus que poseían en Venezuela.

“Acá soy secretaria, recepcionista...allá era la jefa” (Ysmary 47, secretaria).

Los procesos de convalidación de títulos pueden incidir en la dificultad de poder dedicarse a su profesión, como manifiesta Alexy:

"Me venía a conocer otro mundo, y aquí me tocó llegar a empezar de cero. Yo llegué y me fui a la Universidad de Chile, al Ciae...y pues, conocí a algunos docentes, y a algunos investigadores, pero hasta el momento, no he podido ingresar a una investigación, ni como voluntaria, porque era el problema de mis documentos, que no los tenía...y no se me da la oportunidad de dar clases, me tocó hacer otras cosas, trabajé en tiendas, ahorita estoy en un call center.." (52, doctora en ciencias políticas). 
Una categoría central del desarraigo, es la reflexión y nostalgia sobre lo que se deja. En los discursos de los venezolanos se reiteran la familia y amigos, el trabajo, la carrera y el estatus que se había alcanzado. Como señala Héctor, la familia tiene un lugar prioritario:

“yo al tener a mis dos niños, me preparé psicológicamente, los preparé a ellos, explicándole, un poco de lo que ellos podían entender, porque la niña tiene 5 años, y el niño tiene 8 años, y cómo le explicas tú a un niño de que te tienes que ir, por tales razones, pero que pronto los iba a ver." (30, sociólogo).

El trabajo y el desarrollo profesional son las aspiraciones centrales en el imaginario de los venezolanos, poder desempeñarse en la especialidad de cada uno, de modo de no perder el estatus ya logrado, permitiendo un mejor futuro.

Estos desarraigos individuales, sin embargo, no son vividos aisladamente, sino que se suelen retomarse muchos vínculos en Santiago con personas que se conocían allá, lo que hace menos "dura" la salida de su país. Por esta razón dicen ya no necesitar nada de lo que se quedó allá, pues aquí lo tendrían todo. Después de un par de años, no es raro que ya no quede ningún ser querido en Venezuela:

"la gente incluso, amigos, y mucha gente de esta edad, de más o menos 30, de 25, ...no hablo con alguien de Maracaibo desde hace años, y voy caminando por aquí, y nos encontramos... pero eso, extraño solo el clima, porque la comida no, ya se la trajeron y la instalaron aquí también" (Héctor, 30, sociólogo).

Quienes primero han llegado a Chile se trasforman en "puentes", siendo una forma de devolver la mano ya que muchos llegaron también de esa manera, por eso "casi todos los livings tienen cama, porque tienes a alguien" (Juan, 47, arquitecto).

\section{EVALUACIÓN DE LA EXPERIENCIA MIGRATORIA E IMAGINARIOS DE FUTURO: ¿ARRAIGO?}

\subsection{Evaluación de la situación presente}

La experiencia migratoria suele ser evaluada como positiva, en tanto que Chile se les presenta como un lugar seguro y agradable 
para vivir, pudiendo formar una familia y con el paso de los años realizarse laboralmente. Ana destaca la positiva recepción que la sociedad chilena:

"Yo he disfrutado esta tranquilidad que se vive en el día a día ... que yo no tuve en Venezuela por mucho tiempo, entonces... la agradezco, siento que ha habido una receptividad muy potente a nivel de los colegios...en general a nivel laboral pues también he sentido esa apertura" (45, administración).

Sin embargo, su esposo Juan — después de dos años residiendo en Santiago- pone en perspectiva ambos países y los contrastes entre un proyecto "comunista", como denomina el modelo político de su país, y el sistema neoliberal de Chile, quedando disconforme debido al excesivo costo de la vida en Chile:

"Yo estoy en una situación un poco más contradictoria. Por la experiencia de mis dos hijas en estos dos años yo estoy muy agradecido de Chile, a nivel de lo que ha sido la relación de ellas en sus colegios, con sus maestras, con sus compañeros con todo, yo a nivel laboral también, no me quejo, me han tratado bien. Este... pero ya ahora me estoy dando cuenta que Chile es un país muy capitalista...digamos que es el extremo opuesto de lo que somos en Venezuela, en Venezuela hay un comunismo de porquería que nada sirve, entonces aquí yo siento que Chile es un país muy caro, ahora con dos años lo padezco, pero bueno, hay que seguir" (47, arquitecto).

Sobre la posibilidad de retornar o emigrar a otro país, los/as entrevistados/as no consideran la opción de retornar a menos que la situación política-económica de Venezuela realmente mejore. Evalúan que haberse venido a Chile fue una buena opción. Al mismo tiempo, existe una indecisión sobre una nueva migración debido a todo lo que ha costado asentarse. Como dice Luis, ya está establecido:

"Mira, irme a otro país... Siempre me llamó la atención Europa, y me gusta mucho...el único lío allá son los papeles. Actualmente, tengo la posibilidad por mi cuñada que está allá y tiene papeles. El problema es que una vez que tú ya has hecho tu vida acá, estás establecido a pesar de que no tengo tanto igual tengo, ¿cachay? Tienes que pensar en volver a empezar de cero, es otra cosa" (22, sin estudios superiores). 
La re-invención personal lograda a lo largo de la trayectoria migratoria cuestiona la posibilidad de retorno, sin embargo más que de transnacionalismo en el éxodo venezolano estamos ante un caso de diáspora, pues en el imaginario de una Venezuela postMaduro (símbolo de la actual crisis) reside el ideal de futuro, de una buena vida, en lo que implica una idea retrotópica en los términos de Bauman (2017).

\subsection{Emergente convivencia intercultural}

Sobre esta inicial convivencia intercultural, se suele expresar que ha sido positiva. En el ámbito laboral se suelen sentir valorados, como constata Ysmary:

"En el trabajo súper bien. De hecho, siempre cuando llego a la oficina, mucha gente se alegra, a veces me da como vergüenza por las compañeras, porque a veces prefieren que uno las atienda, hablan más con una" (47, secretaria).

Los problemas de adaptación no se refieren a sufrir discriminación, xenofobia ni racismo, sino con no haberse aún acostumbrado a la "forma de ser" de los chilenos, a no entender cómo hablan y algunos hábitos que interpretaban como "hostiles" y que poco a poco empiezan a comprender y aceptar. Surge reiteradamente el tema de que los chilenos serían más "cerrados" que los venezolanos:

"Pasa que los chilenos son reservados, o será que nosotros somos demasiado extrovertidos, puedes ser. Cosas como saludar en el ascensor, nosotros saludamos a todo el mundo, es una norma de educación y tus padres te retaban si no saludabas, en cambio aquí, y hemos hablado con chilenos, que es lo bueno de hablar con ellos, les dijimos '¿por qué no saludan?', y ellos dijeron ‘'pero por qué saludan?' O sea, para ellos es extraño que una persona que no conoces te salude, para nosotros es obligatorio, es lo normal" (Ysmary, 47, secretaria).

Respecto a espacios de encuentro, la festividad más extendida e importante para los venezolanos es la navidad, en que se reúne la familia extensa en torno a la comida típica, las hallacas, durante el mes de diciembre: 
"La navidad para nosotros es como las fiestas patrias para los chilenos, y ahí se dan vacaciones colectivas en la empresa, casi todo el mes, y nosotros teníamos por costumbre, en la familia, irnos a una casa, y encerrarnos una semana o hasta dos semanas, encerrados en una casa grande, y todos los niños, los sobrinos, todos compartíamos. O sea, la navidad en Venezuela es una fiesta de casi todo el mes. La navidad es comer y comer la comida típica" (Juan, 47, arquitecto).

Se destaca la importancia de mantener la propia cultura, revitalizándola, y de ir generando un paulatino mestizaje cultural con la sociedad chilena, como sostiene Marcela:

"Creo que eso es un legado que tiene que dejarles a los hijos, el poder integrar las dos culturas. Sacar lo mejor de cada uno" (40, psicóloga).

\section{CONCLUSIONES}

En el presente texto mostramos cómo los migrantes venezolanos que residen en Santiago viven sus primeros años en Chile, destacando su positiva integración social, aspiraciones y ambivalencia respecto a arraigarse en esta nueva sociedad. La crisis político-económica que vive Venezuela es la principal motivación para emigrar de su país natal. Hay consenso en que desde el año 2014 ha habido un deterioro tanto en la inseguridad (delincuencia) como en las condiciones económicas y laborales, que hacen necesario reinventarse migrando, lo que se aprecia claramente en el gran crecimiento del flujo migratorio de venezolanos/as hacia Chile. Así, los datos demográficos de la migración venezolana muestran que alrededor del año 2014 se produce un quiebre en la tendencia histórica de esta migración, pasando de una migración pequeña a un fuerte incremento que llega a posicionar a los venezolanos/as como uno de los flujos migratorios más importantes que recibe Chile.

Este cambio cuantitativo se refleja en las edades de los y las migrantes, que se han concentrado en las edades laborales $(73,4 \%$ entre 20 y 39 años), por lo que la motivación laboral se posiciona como una de las más importantes. Como se ve en las entrevistas, este cambio tiene directa relación con el fuerte deterioro de las 
condiciones de vida en Venezuela. En las entrevistas se aprecia que para asentarse o no en Chile, se manifiesta como fundamental poder trabajar en la profesión que cada uno estudió (lo que conlleva la dificultad de la convalidación de estudios), aumentar el espacio de residencia cotidiana en los departamentos y adquirir algunos bienes. Estas aspiraciones se han visto favorecidas por la sensación de no ser discriminados en Chile y lograr movilidad socio-económica ascendente.

En la vida cotidiana se perciben ciertas diferencias culturales pero que no devienen en barreras a la integración, lo que se facilita por compartir una misma lengua. Las cualidades asignadas a su propia sociedad y cultura suelen ser superiores a las que asignan a la chilena, destacando que la "forma de ser" de los chilenos es reservada, en oposición a la calidez de la sociedad venezolana, la que también se visualiza como más cohesionada. En este sentido, resulta también importante para el logro de una buena vida mantener los lazos comunitarios co-étnicos, así como ampliarlos con amistades chilenas y de otros colectivos migrantes.

Esta revitalización cultural venezolana en Chile más que coexistir con lazos transnacionales con familiares y amigos que residen en Venezuela, está conformando una situación diaspórica, reencontrándose en Chile con antiguos conocidos o a través de conexiones internacionales con quienes han migrado a otros países. Pese a este imaginario de comunidad, se constata una diversidad interna basada en la polarización política, particularidades regionales y ocupaciones. Asimismo, se relata una experiencia común de transversalidad (mezcla social) en Venezuela y un emergente cierre en Chile a partir de la estratificación económica.

Las formas de vivir, las diferencias culturales, devienen una oportunidad de intercambio y transformación personal. En este aspecto, es fundamental en sus discursos sobre el desafío de integrarse en Chile tanto la percepción de lograr éxito laboral y económico como la experiencia de participar en un paulatino proceso de mestizaje cultural, aportando a la construcción de convivencia intercultural. Estas condiciones están generando arraigo, al menos en el corto plazo. Pero por el momento, dadas las relativamente buenas experiencias que manifiestan vivir en Chile los interlocutores, cabe esperar que se mantenga la tendencia al aumento que este flujo de migrantes ha mostrado en los últimos años.

Ahora bien, la continuidad en el flujo y la calidad de la condición 
migratoria están sujetas a los eventuales cambios en la normativa nacional. De aprobarse el proyecto de Ley de Migraciones que impida el cambio de categoría migratoria (pasar de turista a residente al interior del país), se podría producir una pauperización en la condición migratoria de parte del colectivo venezolano, que podría tender crecientemente a la irregularidad. La creación de la "visa democrática” no parece ser una medida suficiente para asegurar la regularidad de los venezolanos, pues hasta el momento dicha visa ha sido difícil de obtener y no ha facilitado un flujo "ordenado, seguro y regular". Desde el 16 de abril hasta el 20 de agosto de 2018, se han solicitado 64.932 "visas democráticas" y se han otorgado solo $9.626^{9}$. Esto se explica, en parte, por los altos costos y la imposibilidad de acceder a los documentos que el consulado de Chile exige en Venezuela.

\section{BIBLIOGRAFÍA}

Anderson, B. (2007). Comunidades imaginadas. Reflexiones sobre el origen y la difusión del nacionalismo. México: FCE.

Appadurai, A. (2015). El futuro como hecho cultural. Buenos Aires: FCE.

Atisba (2018). Atisba Monitor: El mapa de la inmigración en Santiago. Localización espacial inmigrantes Censo 2017. Santiago: Atisba.

Balibar, E. y Wallerstein, I. (1988). Raza, nación y clase. Madrid: Iepala.

Bourdieu, P. y Wacquant, L. (2012). Una invitación a la sociología reflexiva. Buenos Aires: Siglo XXI.

Bauman, Z. (2017). Retrotopía. Buenos Aires: Paidós.

- (2016). Extraños llamando a la puerta. Barcelona: Paidós.

- (2009). Comunidad. En busca de seguridad en un mundo hostil. Madrid: Siglo XXI.

Bermúdez, Y. S. J. et al. (2018). Informe sobre la movilidad humana venezolana. Realidades y perspectivas de quienes emigran. Servicio Jesuita a Refugiados (SJR), San Cristóbal, Venezuela.

Butler, J. y Spivak, G. (2009). ¿Quién le canta al Estado-nación? Lenguaje, política, pertenencia. Buenos Aires: Paidós.

CASEN (2015). Inmigrantes. Síntesis de resultados. Santiago: Ministerio de Desarrollo Social. Disponible en: http://observatorio.ministeriodesa rrollosocial.gob.cl/casen-multidimensional/casen/docs/casen_nmigrantes_2015.pdf (Recuperado el 10 mayo de 2018).

9 Información otorgada por el Ministerio de Relaciones Exteriores a través de solicitud de transparencia. 
Castoriadis, C. (1998). Hecho y por hacer. Pensar la imaginación. Buenos Aires: Eudeba.

CEPAL y OIT (2017). Coyuntura laboral en América Latina y el Caribe. La inmigración laboral en América Latina. N¹6, Santiago. Disponible en: http://repositorio.cepal.org/bitstream/handle/11362/41370/1/S1700342_ es.pdf (Recuperado el 20 junio de 2018).

Cooperativa (27 de agosto de 2018). Casi 150 mil venezolanos entraron a Chile en los últimos siete meses. Disponible en: https://www.cooperativa. $\mathrm{cl} /$ noticias/pais/poblacion/inmigrantes/casi-150-mil-venezolanosentraron-a-chile-en-los-ultimos-siete-meses/2018-08-27/073030.html (Recuperado el 27 de agosto de 2018).

- (23 de agosto de 2018). ONU pidió una "mejor acogida" a venezolanos en países vecinos. Disponible en: https:/www.cooperativa.cl/noticias/ mundo/organismos-internacionales/onu/onu-pidio-una-mejor-acogidaa-venezolanos-en-paises-vecinos/2018-08-23/115640.html (Recuperado el 24 de agosto de 2018).

De Certeau, M. (2000). La invención de lo cotidiano 1. Artes de hacer. México: Iberoamericana.

De Sousa Santos, B. (2010) Descolonizar el saber, reinventar el poder. Montevideo: Trilce.

Departamento de Extranjería y Migración (DEM) (2018). Minuta población venezolana en Chile. Ministerio del Interior y Seguridad Pública, Santiago.

- (2017). Población Migrante en Chile. Santiago: Ministerio del Interior y Seguridad Pública. Disponible en: http://www.extranjeria.gob.cl/ media/2017/09/RM_PoblacionMigranteChile1.pdf (Recuperado 12 de mayo de 2018).

- (2016). Migración en Chile 2005-2014. Santiago: Ministerio del Interior y Seguridad Pública. Disponible en: http://www.extranjeria.gob.cl/ media/2016/06/Anuario.pdf (Recuperado el 12 marzo de 2018).

- (2011). Requisitos para solicitar la nacionalidad chilena por nacionalización. Disponible en: http://www.extranjeria.gob.cl/filesapp/ NCH\%20ISO.pdf (Recuperado el 19 abril de 2018).

Del Acebo, E. (1996). Sociología del arraigo. Una lectura crítica de la teoría de la ciudad. Buenos Aires: Claridad.

Edson, W. (2016). Articulaciones del desarraigo en América Latina. El drama de los sin hogar y sin mundo. Editorial Pontificia Universidad Javeriana: Bogotá.

EMOL (09 de abril de 2018). Extranjeros en Chile superan el millón 110 mil y el $72 \%$ se concentra en dos regiones: Antofagasta y Metropolitana.

Disponibleen: http://www.emol.com/noticias/Nacional/2018/04/09/901867/ Extranjeros-en-Chile-superan-el-millon-110-mil-y-el-72-se-concentraen-dos-regiones-Antofagasta-y-Metropolitana.html (Recuperado el 10 de abril de 2018). 
Falquet, J. (2009). Repensar las relaciones de sexo, clase y "raza" en la mundialización neoliberal (trad.). En: Elsa Dorlin. Sexe, race, classe. Pour une épistémologie de la domination. PUF CollectionActuel Marx Confrontation, París.

González, A. y Ramírez, M. (2017). “Actitudes de aculturación, sensibilidad intercultural y prejuicio en población autóctona e inmigrante en España”, en Migraciones Internacionales. Alteridad y Procesos Sociopolíticos, F. Aliaga (editor), Universidad Santo Tomás (USTA), Bogotá, Colombia. ISBN: 978-958-631-968-3.Grimson, Alejandro (2015). Los límites de la cultura. Crítica de las teorías de la identidad. Buenos Aires: Siglo XXI.

Instituto Nacional de Estadísticas (INE). Sin Fecha. $2^{\circ}$ Entrega Resultados Definitivos Censo 2017. Instituto Nacional de Estadísticas: Santiago de Chile. Disponible en: http://www.censo2017.cl/wp-content/ uploads/2018/05/presentacion_de_la_segunda_entrega_de_resultados_ censo2017.pdf (Recuperado el 22 marzo de 2018).

INE y DEM. Estimación de personas extranjeras residentes en Chile. Disponible en: https:/www.ine.cl/docs/default-source/default-document-library/ estimaci $\% \mathrm{C} 3 \% \mathrm{~B} 3 n$-de-personas-extranjeras-residentes-en-chile-al-31de-diciembre-de-2018.pdf?sfvrsn=0 (Recuperado el 22 marzo de 2019).

Izquierdo, A. (2000). "El proyecto migratorio y la integración de los extranjeros”, en Revista Estudios de Juventud N49, INJUVE, Madrid. www.injuve. es/sites/default/files/Revista49-3.pdf (Recuperado el 05 marzo de 2018).

Kymlicka, W. (1996). Ciudadanía multicultural. Barcelona: Paidós.

Massey, D. et al. (2005). Worlds in Motion: Understanding International Migration at the End of the Millennium. Nueva York: Oxford.

Martínez, J. y Orrego, C. (2016). Nuevas tendencias y dinámicas migratorias en América Latina y el Caribe. OIM y CEPAL-Serie Población y Desarrollo $\mathrm{N}^{\circ}$ 114. Disponible en: http://repositorio.cepal.org/bitstream/handle/ 11362/39994/1/S1600176_es.pdf (Recuperado el 9 de Junio de 2018).

OBIMID (2016). Informe OBIMID. La Migración en Chile: Breve reporte y caracterización. Madrid: Observatorio Iberoamericano sobre Movilidad Humana, Migraciones y Desarrollo. http://www.upcomillas.es/es/obimid. Organización Internacional para las Migraciones (OIM) (2015). Los migrantes y las ciudades: Nuevas colaboraciones para gestionar la movilidad. Disponible en: http://publications.iom.int/system/files/wmr2015_sp.pdf (Recuperado el 17 de mayo de 2018).

Ortiz, J. y Escolano, S. (2013). "Movilidad residencial del sector de renta alta del Gran Santiago (Chile): hacia el aumento de la complejidad de los patrones socio-espaciales de segregación", Eure, Vol. 39, N¹18, Santiago. Disponible en: http://www.scielo.cl/scielo.php?script=sci_artte xt\&pid=S0250-71612013000300004 (Recuperado el 08 de Julio de 2018).

Portes, A. y Zhou, M. (2012). "La nueva segunda generación: la asimilación segmentada y sus variantes”, en Sociología económica de las migraciones internacionales. Barcelona: Anthropos. 
Rojas, C. y Santoni, A. (2013). “Geografía política del exilio chileno: los diferentes rostros de la solidaridad”, Perfiles Latinoamericanos, Vol. 21, N41, México: Flacso. Disponible en: http://perfilesla.flacso.edu.mx/ index.php/perfilesla/article/view/97

Sassen, S. (2015). Expulsiones. Brutalidad y complejidad en la economía global. Buenos Aires: Katz.

Stefoni, C. y Bonhomme, M. (2015). "Vidas que se tejen en contextos transnacionales: Un recorrido por el trabajo, la familia y las redes sociales". En Rutas migrantes en Chile. Habitar, festejar y trabajar, editado por Walter Imilan, Francisca Márquez y Carolina Stefoni, 16-35. Santiago: Ediciones Universidad Alberto Hurtado.

Tijoux, M. E. y Palominos, S. (2015). Aproximaciones teóricas para el estudio de procesos de racialización y sexualización en los fenómenos migratorios de Chile. Polis (Santiago), 14(42), 247-275.

Wallerstein, I. (1991 [1979]). The capitalist world-economy. Nueva York: Cambridge University Press.

Weil, S. (2014)[1949]. Echar raíces. Madrid: Trotta.

Smith, A. (1997). La identidad nacional. Madrid: Trama. 